CLINICAL STUDY

\title{
Dexamethasone suppression test predicts later development of an impaired adrenal function after a 14-day course of prednisone in healthy volunteers
}

\author{
Stefanie Neidert, Philipp Schuetz, Beat Mueller ${ }^{1}$ and Mirjam Christ-Crain \\ Division of Endocrinology, Diabetes and Clinical Nutrition, Departments of Internal Medicine and Endocrinology, University Hospital Basel, \\ 4055 Basel, Switzerland and ${ }^{1}$ Department of Internal Medicine, Kantonsspital Aarau, 5000 Aarau, Switzerland \\ (Correspondence should be addressed to M Christ-Crain; Email: mirjam.christ-crain@unibas.ch)
}

\begin{abstract}
Background: Suppression of the adrenal function after glucocorticoid treatment is common, potentially dangerous, and unpredictable. Identification of patients at risk is of clinical importance. We hypothesized that the dexamethasone suppression test predicts the development of corticosteroidinduced impaired adrenal function.

Methods: We included 39 healthy male volunteers. After a 1- $\mu \mathrm{g}$ ACTH test, all participants underwent an overnight $0.5-\mathrm{mg}$ dexamethasone suppression test. Participants then took prednisone, $0.5 \mathrm{mg} / \mathrm{kg}$ body weight, for 14-day. After the withdrawal of prednisone, a 1- $\mu$ g ACTH test was performed and a clinical score was assessed on days $1,3,7$, and 21 .

Results: On days 1, 3, 7, and 21, 100, 50, 26.5 and 32.4\% of the participants had a suppressed adrenal function. The risk of developing suppressed adrenal function decreased from 44 to $0 \%$ in patients with cortisol levels after the administration of dexamethasone in the lowest and highest quartiles respectively. Receiver operating curve (ROC) analysis performed to predict a suppressed adrenal function on day 7 after the withdrawal of prednisone showed an area under the curve (AUC) of 0.76 (95\% confidence interval (CI) 0.58-0.89) for cortisol after the administration of dexamethasone, which was in the range of the AUC of 0.78 (95\% CI 0.6-0.9) for pre-intervention cortisol after the administration of ACTH. Basal cortisol before intake of prednisone (AUC 0.62 (95\% CI 0.44-0.78)) and the clinical score (AUC 0.64 (95\% CI 0.45-0.79)) had significantly lower AUCs.

Conclusion: Circulating cortisol levels after a dexamethasone suppression test and a pre-interventionstimulated cortisol level are predictive of later development of a suppressed adrenal function after a 14-day course of prednisone, and are superior to a clinical score or basal cortisol levels. This may allow a more targeted concept for the need of stress prophylaxis after cessation of steroid therapy.
\end{abstract}

European Journal of Endocrinology 162 943-949

\section{Introduction}

Suppression of the hypothalamic-pituitary-adrenal axis (HPA axis) by exogenous glucocorticoid treatment is the most common cause of adrenal insufficiency. Up to $1 \%$ of people in the general population and $2.5 \%$ of those over 70 years of age are exposed to long-term regimens of glucocorticoids, and are thus at risk for side effects $(1,2)$. One of the most worrisome and unpredictable complications is the suppression of the HPA axis, especially after abrupt cessation of glucocorticoid therapy. Neither the dosage or the duration of therapy nor a random plasma cortisol or ACTH measurement is a reliable indicator of subsequent adrenal insufficiency (3-6). Furthermore, clinical symptoms are unspecific and inaccurate in predicting impaired adrenal function $(5,7,8)$. Importantly, in situations of major stress, even mild adrenal insufficiency can be life threatening (3, 9-13).
The dexamethasone suppression test is routinely used to assess the integrity of the HPA axis, and to diagnose hypercortisolism (Cushing's syndrome) $(14,15)$. Furthermore, it provides information about the feedback sensitivity of the HPA axis to cortisol $(14,16,17)$. There is only a small within-subject variation in the feedback system to a dexamethasone suppression test as well as to an ACTH stimulation test, suggesting an intraindividual response of the HPA axis which is fairly stable and thus might be a predictor for suppressed adrenal function $(14,18)$. However, $1 \mathrm{mg}$ of dexamethasone is a too high dose to allow the detection of individual differences in sensitivity of the HPA axis to glucocorticoids because a near total suppression of cortisol levels is observed in almost all the individuals (14). A lower dose of $0.5 \mathrm{mg}$ of dexamethasone enlarges the range of serum cortisol levels, and allows a better discrimination in feedback sensitivity of the HPA axis $(14,19)$. 
The aim of this study was to investigate whether the 'low-dose' dexamethasone suppression test performed before a 14-day course of systemic glucocorticoid treatment predicts the later development of suppressed adrenal function in healthy volunteers.

\section{Materials and methods}

\section{Participants}

From November 2008 to March 2009, we included 39 healthy male volunteers into this prospective study at the outpatient clinic of the University Hospital of Basel, Basel, Switzerland. Participants with acute or chronic illnesses, contraindications to receive ACTH, and a body mass above $30 \mathrm{~kg} / \mathrm{m}^{2}$ or who had taken glucocorticoids within the last 6 months were excluded from the study. The study was approved by the local institutional review board (Ethikkommission beider Basel, Basel, Switzerland), and written informed consent was obtained from all the participants.

At the baseline visit, we performed a clinical

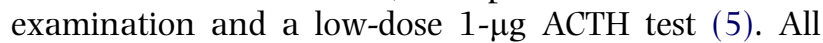
the participants then underwent an overnight $0.5-\mathrm{mg}$ dexamethasone suppression test. Thereby, participants took $0.5 \mathrm{mg}$ of dexamethasone at $2300 \mathrm{~h}$, and a fasting blood sample was collected the next morning at $0800 \mathrm{~h}$ to measure serum cortisol concentrations. Three to 6 days later, the participants started a 14-day course of prednisone at a dose of $0.5 \mathrm{mg} / \mathrm{kg}$ body weight, which was taken each morning. On days $1,3,7$, and 21 after the withdrawal of prednisone, we performed a low-dose ACTH test. In addition, at the same time points, we performed a clinical examination, and a clinical questionnaire was adapted from a published clinical adrenal insufficiency score (20). This previously validated clinical score investigates fatigue, hypoglycemia (fasting glucose $<3.5 \mathrm{mmol} / \mathrm{l}$ ), loss of energy, orthostatic disturbance, hypotonia (systolic blood pressure $<100 \mathrm{mmHg}$ and diastolic blood pressure $<60 \mathrm{mmHg}$ ), reduced strength, sleep disturbance, muscle pain, mood changes, nausea, concentration disturbance, weight loss ( $>3 \mathrm{~kg})$, stomach pain, hyperpigmentation, and eosinophilia (range $0-10$ for each symptom, higher scores indicate greater discomfort) (20). All low-dose ACTH tests were performed in the morning between 0700 and $1100 \mathrm{~h}$. Blood samples were taken at 0 min for the assessment of basal cortisol and $30 \mathrm{~min}$ after i.v. administration of $1 \mu \mathrm{g}$ of ACTH for the measurement of stimulated cortisol concentrations. Blood samples were immediately centrifuged, aliquoted, and stored at $-70{ }^{\circ} \mathrm{C}$ until batch analyses. Cutoffs used to define adrenal insufficiency in the low-dose ACTH test are a matter of controversy. As predefined in our study protocol, we used the cutoff of $550 \mathrm{nmol} / \mathrm{l}$. This was based on prior studies performed in our institution and the endocrine literature, and it is our in-house reference level for the low-dose ACTH test $(18,21-25)$. The advantage of this cutoff is the high sensitivity (however, with only limited specificity). We also calculated our results for different cutoffs described in the literature, i.e. 450 and $500 \mathrm{nmol} / \mathrm{l}$.

\section{Assays and study drug preparation}

Serum total cortisol was measured using a competitive chemiluminescent enzyme immunoassay (Siemens Medical Solutions Diagnostics, Los Angeles, CA, USA) with an analytical sensitivity of $5.5 \mathrm{nmol} / \mathrm{l}$. In patients with values below the detection limit of $27.6 \mathrm{nmol} / \mathrm{l}$, a value of $27.59999 \mathrm{nmol} / \mathrm{l}$ was used for the analysis.

Low-dose $1 \mu \mathrm{g}$ ACTH was prepared by the pharmacy of the University Hospital Basel, and $0.25 \mathrm{mg}$ tetracosactide (Synacthen, Novartis Pharma) was divided into $0.001-\mathrm{mg}$ tetracosactide doses as described elsewhere (5).

\section{Statistical considerations}

The primary outcome of this study was the rate of a suppressed adrenal function assessed on the seventh day after stopping a 14-day course of corticosteroid therapy with $0.5 \mathrm{mg} / \mathrm{kg}$ of prednisone per day. Thereby, a suppressed adrenal function was defined as an inadequate cortisol response to i.v. ACTH $(1 \mu \mathrm{g})$, namely a stimulated plasma cortisol concentration $<550 \mathrm{nmol} / \mathrm{l}$ after $30 \mathrm{~min}$. To compare the prognostic value of individual laboratory markers for the prediction of HPA axis insufficiency, a receiver operating curve (ROC) analysis was performed (26) and the area under the curve (AUC) was used as a measure of overall discriminatory ability.

Data are shown as mean \pm s.D. for normally distributed values, and as median and interquartile range (IQR) for not normally distributed values. To evaluate differences between two groups, paired or unpaired $t$-tests or Wilcoxon rank sum tests were used as appropriate. For categorical values, we used the Fisher's exact test. Correlation analyses were performed using the Pearson or Spearman rank correlation coefficient $(r)$.

A $P$ value $<0.05$ was considered to indicate statistical significance. All calculations were performed using STATA (version 9, StataCorp, TX, USA), Graph Pad Prism (version 4, GraphPad, La Jolla, CA, USA), and MedCalc for Windows (version 7.2.1.0., Mariakerke, Belgium).

\section{Results}

\section{Baseline characteristics}

Of the 39 participants enrolled in this study, 5 were excluded because they were lost to the follow-up $(n=1)$ and did not adhere to the study protocol 
Table 1 Baseline characteristics and follow-up low dose ACTH participants

\begin{tabular}{|c|c|}
\hline Parameter & Median (IQR) \\
\hline Age (years) & $32.5(24.3-40.8)$ \\
\hline Body mass index $\left(\mathrm{kg} / \mathrm{m}^{2}\right)$ & $23.1(21.9-25.5)$ \\
\hline Weight $(\mathrm{kg})$ & $77(70.3-87.3)$ \\
\hline Heart rate (beats/min) & $65.5(61.3-72)$ \\
\hline Systolic blood pressure $(\mathrm{mmHg})$ & $124.5(120-130)$ \\
\hline Diastolic blood pressure $(\mathrm{mmHg})$ & $75(70-80.8)$ \\
\hline Prednisone doses $(\mathrm{mg})$ & $40(35-43.8)$ \\
\hline Cortisol after the administration of $0.5 \mathrm{mg}$ of dexamethasone $(\mathrm{nmol} / \mathrm{l})$ & $39(27.9-72.5)$ \\
\hline Basal cortisol levels at baseline $(\mathrm{nmol} / \mathrm{l})$ & $471.5(328.8-539.5)$ \\
\hline Stimulated cortisol levels at baseline (nmol/l) & $620.5(558.5-688.8)$ \\
\hline Basal cortisol on day 1 after stopping prednisone $(\mathrm{nmol} / \mathrm{l})$ & $114.5(59.8-191.3)$ \\
\hline Stimulated cortisol on day 1 after stopping prednisone (nmol/l) & $226.0(180.8-292.3)$ \\
\hline Basal cortisol on day 3 after stopping prednisone (nmol/l) & $385.0(298.8-498.5)$ \\
\hline Stimulated cortisol on day 3 after stopping prednisone $(\mathrm{nmol} / \mathrm{l})$ & $549.0(491.3-603.3)$ \\
\hline Basal cortisol on day 7 after stopping prednisone $(\mathrm{nmol} / \mathrm{l})$ & $354.5(275.3-480.3)$ \\
\hline Stimulated cortisol on day 7 after stopping prednisone $(\mathrm{nmol} / \mathrm{l})$ & $602.5(552.5-636.0)$ \\
\hline Basal cortisol on day 21 after stopping prednisone $(\mathrm{nmol} / \mathrm{l})$ & $335.0(288.3-401.0)$ \\
\hline Stimulated cortisol on day 21 after stopping prednisone (nmol/l) & $582.5(539.5-625.5)$ \\
\hline
\end{tabular}

$(n=4)$, leaving 34 for the final analysis. Median age of the participants was 32.5 years (IQR 24.3-40.8), and the median dose of weight-adjusted prednisone intake was $40 \mathrm{mg}$ (IQR 35-43.8) per day.

Detailed baseline characteristics, clinical findings, and laboratory data are presented in Table 1.

\section{Dexamethasone suppression test}

Figure 1 shows the distribution of cortisol concentrations before and after the administration of $0.5 \mathrm{mg}$ of dexamethasone. Of the 34 participants, 9 (26.4\%) had a post-dexamethasone cortisol suppression below the detection limit of $27.6 \mathrm{nmol} / \mathrm{l}$. The median cortisol concentration after the administration of $0.5 \mathrm{mg}$ of dexamethasone was $39 \mathrm{nmol} / \mathrm{l}$ (IQR 27.9-72.5).

Cortisol levels after the dexamethasone suppression test correlated with basal cortisol levels at baseline and on day $1(r=0.42, P=0.02 ; r=0.36, P=0.04)$, but not with basal levels on days 3, 7, and 21. In addition, cortisol levels after the dexamethasone suppression test correlated with cortisol levels after low-dose ACTH testing at baseline and on days 7 and $21(r=0.36$, $P=0.04 ; r=0.39, P=0.02 ; r=0.37, P=0.03)$. There was no significant correlation on days 1 and 3 .

\section{Cortisol value after the dexamethasone suppression test to predict a suppressed adrenal function}

The risk of developing a suppressed adrenal function on day 7 was increased in patients with low cortisol levels after dexamethasone suppression test. Figure 2 shows quartiles of cortisol levels after dexamethasone suppression test and the percentage of patients who did and did not develop adrenal failure. As demonstrated, the risk of developing a suppressed adrenal function decreased from $44 \%$ in patients with cortisol levels after the administration of dexamethasone in the lowest quartile to $0 \%$ in patients with cortisol after the administration of dexamethasone in the highest quartile.

To compare cortisol levels after the administration of dexamethasone with other parameters and to predict a suppressed adrenal function on day 7 , we performed ROC analysis. Sensitivity was calculated in those participants in whom the low-dose ACTH test was inadequate, and specificity was assessed in those patients in whom it was normal. The AUC for cortisol after the administration of dexamethasone to predict a later suppressed adrenal function was 0.76

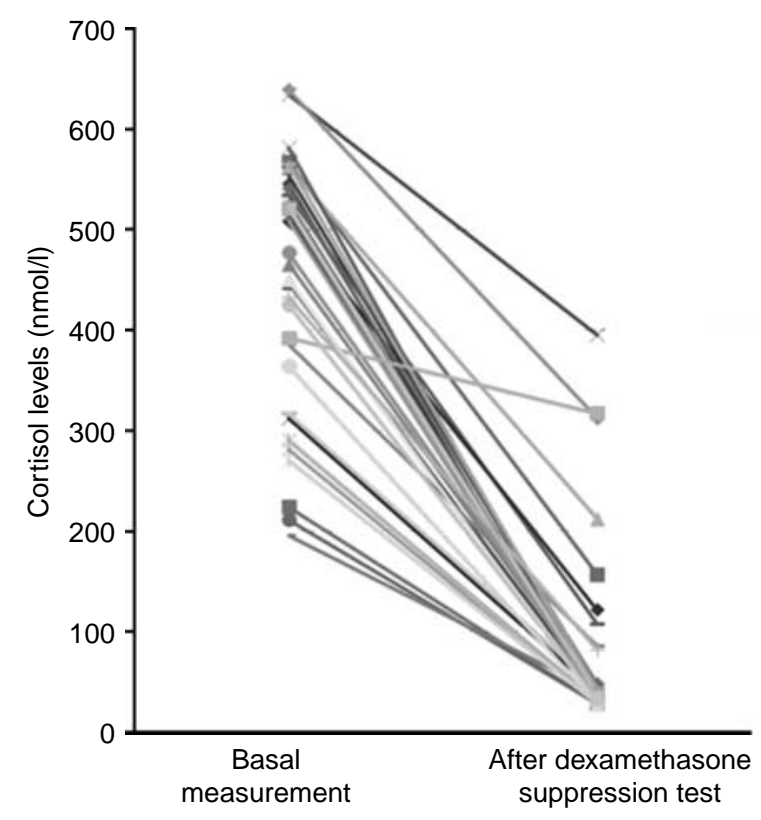

Figure 1 Cortisol concentrations before and after the administration of $0.5 \mathrm{mg}$ of dexamethasone. 


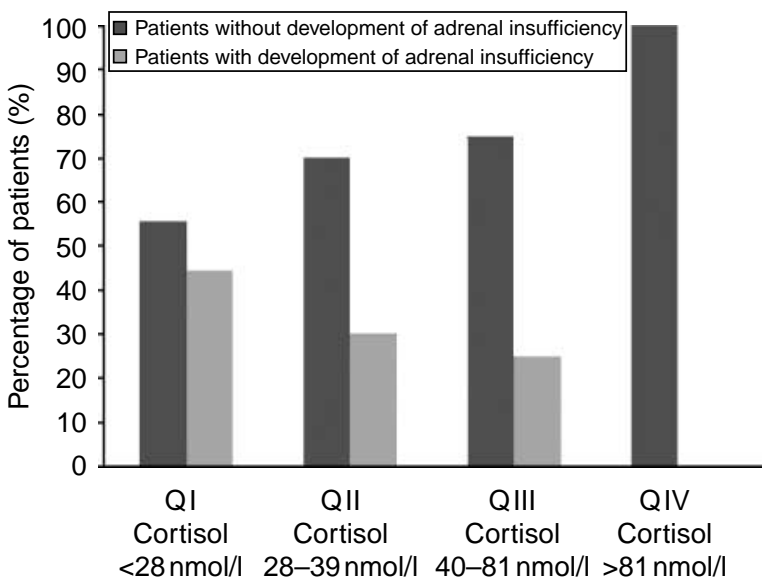

Figure 2 Quartiles of cortisol levels after dexamethasone suppression test and the percentage of patients who did and did not develop adrenal failure.

(95\% confidence interval (CI) 0.58-0.89), which was in the range of the pre-intervention cortisol value after ACTH stimulation with an AUC of $0.78 \quad(95 \%$ CI $0.60-0.90)$. Both were higher compared with basal cortisol measured before the intake of prednisone (AUC 0.62 (95\% CI $0.44-0.78), P=0.22, P=0.07)$ and the clinical score (AUC 0.64 (95\% CI 0.45-0.79), $P=0.35$, $P=0.19$; Fig. 3). A cutoff level of cortisol after dexamethasone had a sensitivity of $77 \% \quad(95 \%$ CI 40-97) and a specificity of 76\% (95\% CI 55-91). A cutoff level of cortisol after dexamethasone showed a specificity of $80 \%(95 \%$ CI 59-93) with a sensitivity of $44 \%$ (95\% CI $14-79)$. Similarly, a cutoff level of $81 \mathrm{nmol} / \mathrm{l}$ had a sensitivity of $100 \%(95 \%$ CI $66-100)$ with a specificity of $32 \%(95 \%$ CI $15-54)$.

\section{Frequency of a suppressed adrenal function in patients with cortisol levels of $\leq$ or $>32 \mathrm{nmol} / \mathrm{l}$ after the administration of dexamethasone}

In participants with a cortisol level after dexamethasone $\leq 32 \mathrm{nmol} / \mathrm{l}$, a suppressed adrenal function occurred in $23,100,61.5,53.9$, and $46.2 \%$ at baseline and on days $1,3,7$, and 21 respectively compared with $14.3,100$, $42.9,9.5$, and $23.8 \%$ respectively when cortisol after the administration of dexamethasone was $>32 \mathrm{nmol} / \mathrm{l}$ $(P=0.21$, NS, $P=0.29, P=0.01$ and $P=0.26$; Table 2).

When using a cutoff level of $500 \mathrm{nmol} / \mathrm{l}$, a suppressed adrenal function occurred in participants with a cortisol level after dexamethasone $\leq 32 \mathrm{nmol} / \mathrm{l}$ in $38.5,100$, 23,23 , and $15.4 \%$ at baseline and on days $1,3,7$, and 21 respectively compared with $0,95.2,28.6,4.8$, and $14.3 \%$ respectively when cortisol after the administration of dexamethasone was $>32 \mathrm{nmol} / \mathrm{l}(P=0.048$, $P=1, P=1, P=0.27$ and $P=1)$.
Using a cutoff level of $450 \mathrm{nmol} / \mathrm{l}$, a suppressed adrenal function occurred in participants with a cortisol level after dexamethasone $\leq 32 \mathrm{nmol} / \mathrm{l}$ in $0,100,23$, 0 , and $7.7 \%$ at baseline and on days $1,3,7$, and 21 respectively compared with $0,95.2,19,0$, and $9.5 \%$ respectively when cortisol after the administration of dexamethasone was $>32 \mathrm{nmol} / \mathrm{l}(\mathrm{NS}, P=1, P=1$, NS and $P=1$ ).

In patients with a cortisol level after dexamethasone $\leq 32 \mathrm{nmol} / \mathrm{l}$, median basal cortisol levels were lower on day 21 (320 nmol/l (IQR 284-331)) compared with patients with cortisol levels after dexamethasone $>32 \mathrm{nmol} / \mathrm{l}$ (364 nmol/l (IQR 315-417), P=0.049). There was no difference between these two groups in basal cortisol levels on days 1,3 , and 7 respectively (Fig. 4).

In patients with a cortisol level after the administration of $\leq 32$ or $>32 \mathrm{nmol} / \mathrm{l}$ of dexamethasone respectively, median cortisol levels after ACTH testing were significantly lower on day $7(549 \mathrm{nmol} / \mathrm{l}$ (IQR 508-599) vs $618 \mathrm{nmol} / \mathrm{l}$ (IQR 596-673), $P=0.0057)$ and on day $21 \quad(566 \mathrm{nmol} / \mathrm{l}$ (IQR 535-577) vs $610 \mathrm{nmol} / \mathrm{l}$ (IQR 555-715), $P=0.03$ ). There was no difference in cortisol levels between these two groups after ACTH testing on days 1 and 3 (Fig. 4).

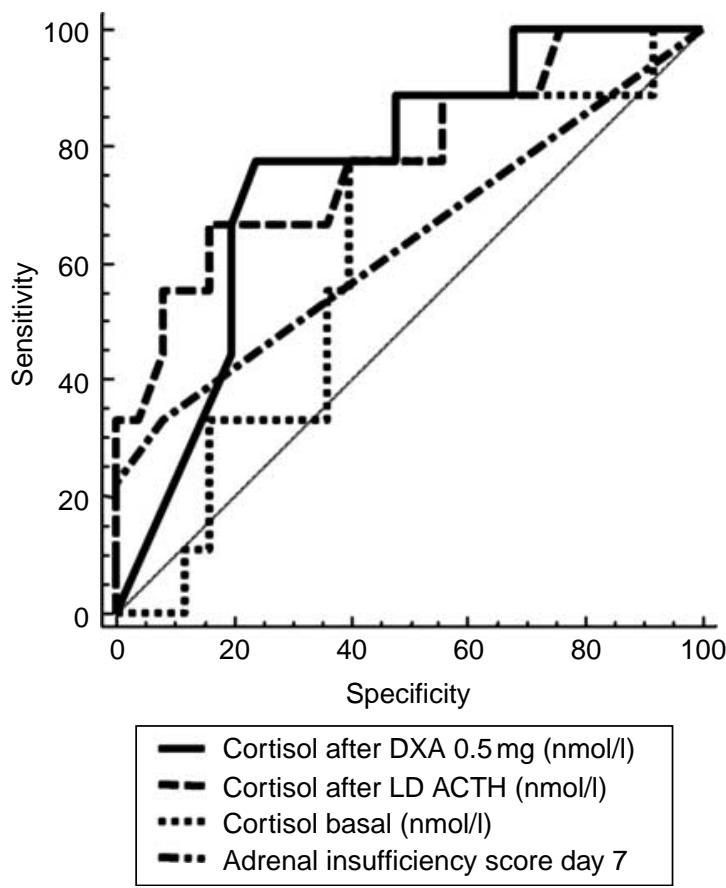

Figure 3 Comparison of ROC analysis to predict adrenal insufficiency for basal cortisol, stimulated cortisol after the administration of ACTH, cortisol after intake of $0.5 \mathrm{mg}$ of prednisone, and clinical score. DXA, dexamethasone; LD ACTH, low-dose ACTH. 
Table 2 Number of participants with a suppressed adrenal function defined as stimulated cortisol levels below $550 \mathrm{nmol} / \mathrm{l}(n(\%))$.

\begin{tabular}{lccc}
\hline & $\begin{array}{c}\text { Cortisol level after } \\
\text { dexamethasone } \\
\leq \mathbf{3 2} \text { nmol//I } \\
(n=13)\end{array}$ & $\begin{array}{c}\text { Cortisol level after } \\
\text { dexamethasone } \\
>\mathbf{3 2} \text { nmol// } \\
(n=21)\end{array}$ & $\boldsymbol{P}$ \\
\hline Baseline & $5(23 \%)$ & $3(14.3 \%)$ & 0.21 \\
Day 1 & $13(100 \%)$ & $21(100 \%)$ & NA \\
Day 3 & $8(61.5 \%)$ & $9(42.9 \%)$ & 0.29 \\
Day 7 & $7(53.9 \%)$ & $2(9.5 \%)$ & 0.01 \\
Day 21 & $6(46.2 \%)$ & $5(23.8 \%)$ & 0.26 \\
\hline
\end{tabular}

\section{Clinical score}

The clinical symptom score assessed at all follow-up visits was not discriminative among the participants with normal and suppressed adrenal function.

\section{Discussion}

This is the first prospective study to investigate the predictive value of a dexamethasone suppression test to predict subsequent development of adrenal failure. Unlike a clinical symptom score, cortisol levels after a dexamethasone suppression test are predictors for suppressed adrenal function on day 7 after stopping prednisone in healthy volunteers undergoing a 14-day course of prednisone treatment at a dose of $0.5 \mathrm{mg} / \mathrm{kg}$ body weight.

The dexamethasone suppression test gives information about the feedback sensitivity of the HPA axis to cortisol $(14,16,17)$. A previous study showed a good correlation between basal cortisol levels and cortisol levels after a dexamethasone suppression test indicating that there is a set point for HPA axis activity, which is defined before as well as after a low-dose dexamethasone suppression test (14). In addition, serum cortisol levels after the administration of dexamethasone showed an individual stability, indicating that the HPA axis is set at a stable and reproducible set point for a certain individual (14). In our study, patients with a cortisol level after the administration of dexamethasone in the lowest quartile had a $44 \%$ risk of developing an impaired adrenal response. A cutoff value for cortisol after dexamethasone of $32 \mathrm{nmol} / \mathrm{l}$ had a sensitivity of $77 \%$ and a specificity of $76 \%$ to predict a suppressed adrenal function on day 7 after stopping a 14-day course of glucocorticoid treatment. Reducing the cutoff levels showed even better specificity (e.g. a cortisol level after the administration of $<27.6 \mathrm{nmol} / \mathrm{l}$ of dexamethasone had a $100 \%$ specificity) for early recognition of those people at high risk for a suppressed adrenal function who should have follow-up adrenal function tests, and receive stress prophylaxis and an emergency set after the cessation of glucocorticoids. Similarly, participants in the highest quartile of cortisol levels after dexamethasone suppression test had a low risk (in our cohort no risk, to the extent that no case was found) of adrenal failure. Hence, people with a cortisol level after dexamethasone-suppression-test of $81 \mathrm{nmol} / \mathrm{l}$ had no risk of adrenal failure, and thus may not need close monitoring. This cutoff had a sensitivity of $100 \%$ and a specificity of $32 \%$ to exclude adrenal impairment after glucocorticoid intake. In addition, stimulated cortisol levels after ACTH injection at baseline were also of good value to predict a suppressed adrenal function after glucocorticoid intake. Thus, the more a patient is able to
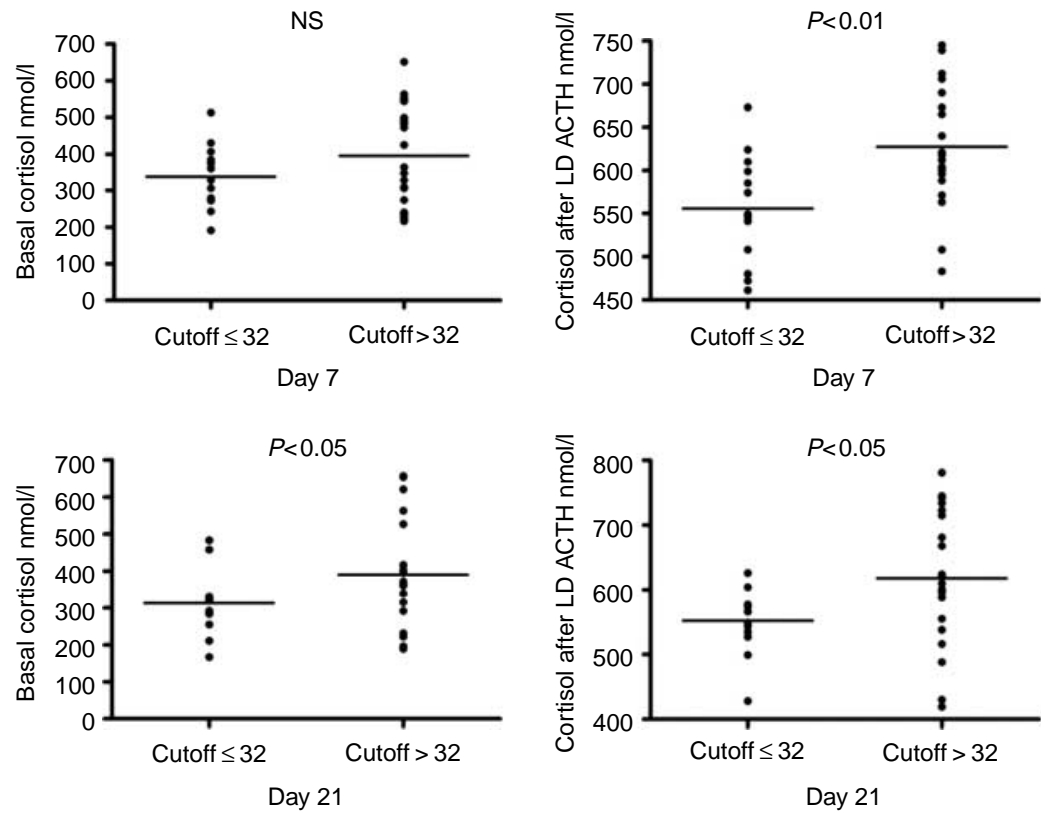

Figure 4 Basal and stimulated cortisol levels of participants with a cutoff level of cortisol after dexamethasone $\leq 32$ or $>32 \mathrm{nmol} / \mathrm{l}$ on days 7 and 21 after stopping oral prednisone intake. The median level is shown with aligned dot plots representing the absolute values. 
increase his/her cortisol reserves after ACTH stimulation, the less he or she will suppress the HPA axis after steroid intake. As far as our knowledge goes, this is the first study to assess a stimulated cortisol value as a parameter to predict adrenal dysfunction after glucocorticoid intake. In contrast, a baseline cortisol level measured before the intake of prednisone was of limited value to predict a later suppressed adrenal function in our study.

Hereditary factors play a critical role in the regulation of the HPA axis. Relevant genes include those that encode receptors, transcription factors, and enzymes involved in hormone synthesis or target cell function $(2,3,10,27-29)$. This can lead either to an increase in the activation of the HPA axis activity or to an impaired adrenal function (3, 27-29). Genetic factors predicting an impaired adrenal function after glucocorticoid intake are not yet known.

The clinical symptom score, which assesses typical symptoms of an adrenal insufficiency, was nonspecific and inaccurate in predicting a suppressed adrenal function. Thus, clinical symptoms may be misleading in predicting adrenal insufficiency. On the other hand, laboratory tests should never be interpreted outside of the clinical context in practice.

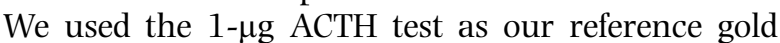
standard to evaluate adrenal function. This low-dose ACTH test has been found to detect serum ACTH levels comparable to those encountered in stressful situations and in other stimulation tests (30-32). However, this issue is debated $(22,23,30,32-36)$, and some studies suggested that this test is too sensitive, especially in diagnosing secondary adrenal insufficiency $(22,23,30$, 36). Secondary or tertiary adrenal insufficiency is often diagnosed without additional confirmation tests, and thus, false positive tests may lead to a lifelong steroid replacement therapy in euadrenal patients. In agreement with these studies, $23.5 \%(n=8)$ of our study participants had an inadequate increase of cortisol due to ACTH stimulation already at baseline, also suggesting that the low-dose ACTH test is a highly sensitive measure to assess adrenal function in healthy subjects and that it may overestimate adrenal failure. In addition, there is controversy about the precise cutoff level where a stimulated cortisol level after low-dose testing predicts adrenal insufficiency. Cortisol levels after the administration of 440-600 nmol/l of ACTH have been clinically applied to diagnose adrenal insufficiency, depending on the cause and chronicity of adrenal insufficiency $(2,18,22,30,32$, $33,35,36)$. The cortisol response to the low-dose ACTH test in our cohort varied substantially. Depending on the cutoff levels used, none (cutoff level $440 \mathrm{nmol} / \mathrm{l}$ ) to $44 \%$ (cutoff level $600 \mathrm{nmol} / \mathrm{l}$ ) of our participants would have been classified as adrenal insufficient.

Our study has limitations. First, our study is a proof of principle study, where we included healthy volunteers without co-medication limiting the generalizability of our findings. Importantly, in clinical routine, patients have co-medication and concomitant illness, and there are many factors such as acute illness, anxiety, alcoholism and high estrogen states that interfere with the results of the dexamethasone suppression test. Secondly, we chose the prednisone dose depending on body weight, but used a fixed dexamethasone dose because of an easier feasibility and mirroring routine procedures in clinical practice. Thirdly, the number of included participants is small, and future studies are needed to prospectively validate the proposed cutoff levels for cortisol after the administration of dexamethasone in the prediction of adrenal insufficiency. Finally, we used the low-dose ACTH test with a cutoff of $550 \mathrm{nmol} / \mathrm{l}$ as a reference gold standard to predict adrenal insufficiency. This is controversial, and future studies should investigate the value of the dexamethasone suppression test to predict a suppressed adrenal function after an insulin hypoglycemia test or the standard-dose ACTH test.

In conclusion, we showed for the first time that a dexamethasone suppression test done prior to a 14-day treatment of prednisone at a dose of $0.5 \mathrm{mg} / \mathrm{kg}$ body weight as well as pre-intervention ACTH-stimulated cortisol predicts the development of a suppressed adrenal function on day 7 after stopping a 14-day course of prednisone in healthy volunteers. If confirmed in future studies, a more targeted concept for the need of stress prophylaxis after the cessation of steroid therapy may be envisioned.

\section{Declaration of interest}

The authors declare that there is no conflict of interest that could be perceived as prejudicing the impartiality of the research reported.

\section{Funding}

This research did not receive any specific grant from any funding agency in the public, commercial, or not-for-profit sector.

\section{Acknowledgements}

We are grateful to the nurses and technicians in the Division of Endocrinology, Diabetes and Clinical Nutrition for their indispensable assistance and help in collecting the data and performing the tests.

\section{Author contribution statement}

M Christ-Crain and B Mueller had the idea of the study. S Neidert, M Christ-Crain, and B Mueller drafted the protocol, and S Neidert recruited the subjects and collected the data. S Neidert, P Schuetz, and M Christ-Crain did the analyses and wrote the report. P Schuetz supervised the statistical analysis. All authors read and approved the final manuscript.

\section{References}

1 van Staa TP, Leufkens HG, Abenhaim L, Begaud B, Zhang B \& Cooper C. Use of oral corticosteroids in the United Kingdom. Quarterly Journal of Medicine 200093 105-111. 
2 Bornstein SR. Predisposing factors for adrenal insufficiency. New England Journal of Medicine $20093602328-2339$.

3 Oelkers W. Adrenal insufficiency. New England Journal of Medicine $19963351206-1212$.

4 Grinspoon SK \& Biller BM. Clinical review 62: laboratory assessment of adrenal insufficiency. Journal of Clinical Endocrinology and Metabolism 199479 923-931.

5 Henzen C, Suter A, Lerch E, Urbinelli R, Schorno XH \& Briner VA. Suppression and recovery of adrenal response after short-term, high-dose glucocorticoid treatment. Lancet 2000355 542-545.

6 Schlaghecke R, Kornely E, Santen RT \& Ridderskamp P. The effect of long-term glucocorticoid therapy on pituitary-adrenal responses to exogenous corticotropin-releasing hormone. New England Journal of Medicine 1992326 226-230.

7 Salassa RM, Bennett WA, Keating FR Jr \& Sprague RG. Postoperative adrenal cortical insufficiency; occurrence in patients previously treated with cortisone. Journal of the American Medical Association 1953152 1509-1515.

8 Schuetz P, Christ-Crain M, Schild U, Suess E, Facompre M, Baty F, Nusbaumer C, Brutsche M \& Muller B. Effect of a 14-day course of systemic corticosteroids on the hypothalamic-pituitary-adrenalaxis in patients with acute exacerbation of chronic obstructive pulmonary disease. BMC Pulmonary Medicine $2008 \mathbf{8} 1$.

9 Werbel SS \& Ober KP. Acute adrenal insufficiency. Endocrinology and Metabolism Clinics of North America 199322 303-328.

10 Arlt $\mathrm{W}$. The approach to the adult with newly diagnosed adrenal insufficiency. Journal of Clinical Endocrinology and Metabolism 2009 94 1059-1067.

11 Bouillon R. Acute adrenal insufficiency. Endocrinology and Metabolism Clinics of North America 200635 767-775.

12 Cooper MS \& Stewart PM. Corticosteroid insufficiency in acutely ill patients. New England Journal of Medicine 2003348 727-734.

13 Mortimer KJ, Tata LJ, Smith CJ, West J, Harrison TW, Tattersfield AE \& Hubbard RB. Oral and inhaled corticosteroids and adrenal insufficiency: a case-control study. Thorax $2006 \mathbf{6 1}$ $405-408$.

14 Huizenga NA, Koper JW, de Lange P, Pols HA, Stolk RP, Grobbee DE, de Jong FH \& Lamberts SW. Interperson variability but intraperson stability of baseline plasma cortisol concentrations, and its relation to feedback sensitivity of the hypothalamo-pituitary-adrenal axis to a low dose of dexamethasone in elderly individuals. Journal of Clinical Endocrinology and Metabolism $19988347-54$

15 Nugent CA, Nichols T \& Tyler FH. Diagnosis of Cushing's syndrome; single dose dexamethasone suppression test. Archives of Internal Medicine $1965116172-176$.

16 Gaab J, Huster D, Peisen R, Engert V, Schad T, Schurmeyer TH \& Ehlert U. Low-dose dexamethasone suppression test in chronic fatigue syndrome and health. Psychosomatic Medicine 200264 311-318

17 Carroll BJ. Dexamethasone suppression test for depression. Advances in Biochemical Psychopharmacology 198439 179-188.

18 Widmer IE, Puder JJ, Konig C, Pargger H, Zerkowski HR, Girard J \& Muller B. Cortisol response in relation to the severity of stress and illness. Journal of Clinical Endocrinology and Metabolism 200590 4579-4586.

19 Pasquali R, Ambrosi B, Armanini D, Cavagnini F, Uberti ED, Del Rio G, de Pergola G, Maccario M, Mantero F, Marugo M, Rotella CM \& Vettor R. Cortisol and ACTH response to oral dexamethasone in obesity and effects of sex, body fat distribution, and dexamethasone concentrations: a dose-response study. Journal of Clinical Endocrinology and Metabolism 2002 87 $166-175$

20 Arlt W, Rosenthal C, Hahner S \& Allolio B. Quality of glucocorticoid replacement in adrenal insufficiency: clinical assessment vs timed serum cortisol measurements. Clinical Endocrinology $2006 \mathbf{6 4} 384-389$.
21 Abdu TA, Elhadd TA, Neary R \& Clayton RN. Comparison of the low dose short synacthen test $(1 \mu \mathrm{g})$, the conventional dose short synacthen test $(250 \mu \mathrm{g})$, and the insulin tolerance test for assessment of the hypothalamo-pituitary-adrenal axis in patients with pituitary disease. Journal of Clinical Endocrinology and Metabolism $1999 \mathbf{8 4} 838-843$.

22 Dorin RI, Oualls CR \& Crapo LM. Diagnosis of adrenal insufficiency. Annals of Internal Medicine 2003139 194-204.

23 Suliman AM, Smith TP, Labib M, Fiad TM \& McKenna TJ. The lowdose ACTH test does not provide a useful assessment of the hypothalamic-pituitary-adrenal axis in secondary adrenal insufficiency. Clinical Endocrinology 200256 533-539.

24 Reimondo G, Bovio S, Allasino B, Terzolo M \& Angeli A. Secondary hypoadrenalism. Pituitary 200811 147-154.

25 Clayton RN. Short synacthen test versus insulin stress test for assessment of the hypothalmo-pituitary-adrenal axis: controversy revisited. Clinical Endocrinology 199644 147-149.

26 DeLong ER, DeLong DM \& Clarke-Pearson DL. Comparing the areas under two or more correlated receiver operating characteristic curves: a nonparametric approach. Biometrics $1988 \mathbf{4 4}$ $837-845$.

27 Charmandari E, Kino T. Ichijo T \& Chrousos GP. Generalized glucocorticoid resistance: clinical aspects, molecular mechanisms, and implications of a rare genetic disorder. Journal of Clinical Endocrinology and Metabolism 200893 1563-1572.

28 Arlt W \& Allolio B. Adrenal insufficiency. Lancet 2003361 $1881-1893$.

29 Russcher H, Smit P, van Rossum EF, van den Akker EL, Brinkmann AO, de Heide LJ, de Jong FH, Koper JW \& Lamberts SW. Strategies for the characterization of disorders in cortisol sensitivity. Journal of Clinical Endocrinology and Metabolism 200691 694-701.

30 Rasmuson S, Olsson T \& Hagg E. A low dose ACTH test to assess the function of the hypothalamic-pituitary-adrenal axis. Clinical Endocrinology $1996 \mathbf{4 4} 151-156$.

31 Nye EJ, Grice JE, Hockings GI, Strakosch CR, Crosbie GV, Walters MM \& Jackson RV. Comparison of adrenocorticotropin (ACTH) stimulation tests and insulin hypoglycemia in normal humans: low dose, standard high dose, and 8-hour ACTH-(1-24) infusion tests. Journal of Clinical Endocrinology and Metabolism $1999843648-3655$.

32 Mayenknecht J, Diederich S, Bahr V, Plockinger U \& Oelkers W. Comparison of low and high dose corticotropin stimulation tests in patients with pituitary disease. Journal of Clinical Endocrinology and Metabolism 199883 1558-1562.

33 Dickstein G \& Saiegh L. Low-dose and high-dose adrenocorticotropin testing: indications and shortcomings. Current Opinion in Endocrinology, Diabetes and Obesity 200815 244-249.

34 Dickstein G. High-dose and low-dose cosyntropin stimulation tests for diagnosis of adrenal insufficiency. Annals of Internal Medicine $2004140312-313$.

35 Kazlauskaite R, Evans AT, Villabona CV, Abdu TA, Ambrosi B, Atkinson $\mathrm{AB}$, Choi $\mathrm{CH}$, Clayton RN, Courtney $\mathrm{CH}$, Gonc EN, Maghnie M, Rose SR, Soule SG \& Tordjman K. Corticotropin tests for hypothalamic-pituitary-adrenal insufficiency: a metaanalysis. Journal of Clinical Endocrinology and Metabolism 200893 $4245-4253$.

36 Tordjman K, Jaffe A, Grazas N, Apter C \& Stern N. The role of the low dose $(1 \mu \mathrm{g})$ adrenocorticotropin test in the evaluation of patients with pituitary diseases. Journal of Clinical Endocrinology and Metabolism 199580 1301-1305.

Received 5 February 2010

Accepted 7 February 2010 